\title{
Aporte e estoque de serapilheira no Brasil: uma análise bibliométrica da produção científica de 2008 a 2019
}

Litterfall and litter Stock in Brazil: a bibliometric analysis of scientific production from 2008 to 2019

\author{
J. I. de M. Rodrigues*1; L. F. F. do Amaral ${ }^{1}$; W. B. R. Martins ${ }^{2}$; H. B. dos Santos \\ Junior $^{3}$; L. S. V.-B. Amorim ${ }^{1}$; L. G. T. Rangel-Vasconcelos ${ }^{1}$ \\ ${ }^{1}$ Laboratório de Manejo de Ecossistemas e Bacias Hidrográficas, Universidade Federal Rural da Amazônia, 66077- \\ 830, Belém-PA, Brasil \\ 2Programa de pós-graduação em Ciências Ambientais, Universidade do Estado do Pará, 66095-015, Belém-PA, Brasil \\ 3Programa de pós Graduação em Ciências Florestais, Universidade Federal Rural da Amazônia, 66077-830, Belém- \\ PA, Brasil
}

* juliaisabellarodrigues@gmail.com

(Recebido em 10 de abril de 2021; aceito em 13 de junho de 2021)

\begin{abstract}
A ciclagem de nutrientes é um processo chave na manutenção de florestas tropicais. A importância da serapilheira na ciclagem de nutrientes é um tema relevante e vem se tornando a base de diversos estudos nas últimas décadas. Com o objetivo de realizar uma análise quali-quantitativa sobre os estudos de serapilheira no Brasil, foi realizada uma bibliometria da produção científica no período de 2008-2019. Analisamos 119 artigos, distribuídos em 19 periódicos. O ano de 2015 apresentou o maior número de publicação com 18 artigos. O estado do Rio de Janeiro representou 13,45\% da produção cientifica, e o bioma Mata Atlântica concentrou 55,72\% das publicações, o que pode estar relacionado à presença das Fundações de Apoio à Pesquisa que mais investem na ciência brasileira. Mais da metade das publicações realizaram pesquisas em apenas um ecossistema. Do total de publicações, $71,4 \%$ quantificou o aporte da serapilheira, enquanto 21,9\% o estoque. Os maiores valores de massa seca de serapilheira foram registrados no bioma Amazônia, com 8,32 $\pm 2,57 \mathrm{Mg} \mathrm{ha}^{-1}$ ano $^{-1}$ e nos ecossistemas caracterizados como floresta primária, com 8,19 $\pm 3,27 \mathrm{Mg} \mathrm{ha}^{-1}$ $a^{-1}$. Para o estoque, os estudos realizados no Cerrado apresentaram as maiores médias, com 7,24 $\pm 1,98$ $\mathrm{Mg} \mathrm{ha}^{-1}$. Os resultados demonstraram que o número de publicações se concentra em determinadas regiões brasileiras. Além disso, percebem os que o maior número de estudos em ecossistemas de plantio monoespecífico e misto pode estar relacionado à importância ecológica e econômica para o Brasil.
\end{abstract}

Palavras-chave: ciclo biogeoquímico, meta-análise, dinâmica de serapilheira.

Nutrient cycling is a key process in maintaining tropical forests. The importance of litter in the cycling of nutrients is a relevant topic and has become the basis of several studies in recent decades. In order to carry out a quali-quantitative analysis of litter studies in Brazil, a bibliometric of scientific production in the period 2008-2019 was carried out. We analyzed 119 articles, distributed in 19 journals. The year 2015 presented the largest number of publications with 18 articles. The state of Rio de Janeiro represented $13.45 \%$ of scientific production, and the Atlantic Forest biome concentrated $55.72 \%$ of publications, which may be related to the presence of the Research Support Foundations that most invest in Brazilian science. More than half of the publications carried out research in only one ecosystem. Of the total number of publications, $71.4 \%$ quantified the litterfall, while $21.9 \%$ the stock. The highest values of dry litter mass were recorded in the Amazon biome, with $8.32 \pm 2.57 \mathrm{Mg} \mathrm{ha}^{-1}$ year- $^{-1}$ and in ecosystems characterized as primary forest, with $8.19 \pm 3.27 \mathrm{Mg}$ ha- ${ }^{-1}$ year. ${ }^{-1}$. For the stock, studies carried out in the Cerrado showed the highest averages, with $7.24 \pm 1.98$ Mg ha- ${ }^{-1}$. The results showed that the number of publications is concentrated in certain Brazilian regions. In addition, those who realize that the largest number of studies in monospecific and mixed planting ecosystems may be related to the ecological and economic importance for Brazil.

Keywords: biogeochemical cycle, meta-analysis, litter dynamics.

\section{INTRODUÇÃO}

A economia brasileira depende, principalmente, das atividades relacionadas à exploração de recursos naturais renováveis e não renováveis como a agropecuária e a mineração, as quais contribuem com a maior parte da arrecadação financeira do país [1-3]. Entretanto, apesar do benefício econômico, essas atividades são responsáveis pela permanência do Brasil no ranking dos 
países que mais desmatam $[4,5]$, isso porque, para a realização dessas atividades torna-se necessária a conversão completa ou parcial da vegetação nativa. A supressão vegetal, causa impactos a nível local e em toda paisagem, provocando intensos distúrbios ecológicos, em sua maioria, associados diretamente à interrupção do ciclo biogeoquímico também gerando consequências relacionadas às mudanças climáticas [6].

No ciclo biogeoquímico, a dinâmica de serapilheira é indispensável, pois seu aporte garante a formação de uma camada de resíduos florestais que além da melhoria das propriedades físicas, devolvem ao solo os nutrientes necessários para o desenvolvimento vegetal, por meio da decomposição [7]. Nesse sentido, a decomposição da serapilheira é um processo chave para a manutenção e equilíbrio dos ecossistemas, pois contribui para a ciclagem de nutrientes $[8,9]$. A serapilheira é caracterizada como todo material vegetal produzido pelos componentes senescentes das plantas, como as folhas, fragmentos de cascas, galhos, flores, inflorescências, frutos e restos vegetais não identificáveis [10,12]. A adição deste material no solo promove a entrada da matéria orgânica e ainda a proteção do próprio solo contra processos erosivos [11, 13]. Somado a isso, a serapilheira também proporciona um micro sítio favorável para o estabelecimento e reprodução da fauna do solo, pela promoção da estabilidade de agregados promovendo a aeração e a manutenção da umidade, proporcionando condições para o desenvolvimento radicular das plantas $[14,15]$.

Para as estimativas de aporte e estoque da serapilheira, utiliza-se normalmente dois métodos de coleta: $1^{\circ}$ ) aporte, constituído por todo material vegetal que cai da parte aérea da planta; apresentando unidade de medida dinâmica de massa por unidade de área, por unidade de tempo; $2^{\circ}$ ) estoque, material de origem vegetal e/ou animal que se encontra sobre o solo florestal; possui unidade de medida expressa pela massa por unidade de área [16]. O aporte, pode ser amostrado mensalmente durante pelo menos um ano em coletores suspensos, com dimensões que variam normalmente de $0,25 \mathrm{~m}^{2}$ a $1 \mathrm{~m}^{2}$. A avaliação do estoque é realizada com coletores de ferro, alumínio ou outro material que é lançado sobre o solo e a serapilheira interna é retirada para análise [16].

Os valores de massa e nutrientes do aporte e do estoque de serapilheira são influenciados por fatores abióticos como àqueles inerentes à própria composição florística, precipitação pluviométrica e radiação solar [17-19], havendo uma relação diretamente proporcional da biomassa e diversidade florística com o acúmulo de serapilheira [20]. Entretanto, mesmo que não haja elevada diversidade, deve-se observar as características fisiológicas das espécies, pois algumas são caducifólias, semi-caducifólia e perenifólias [21]. Em florestas tropicais com períodos secos sazonais há uma maior quantidade de material depositado sobre o solo em períodos mais secos, sendo isso, uma estratégia de controle de perda de água por transpiração [22, 23].

Neste cenário, em função da sua importância ambiental, a serapilheira vem sendo alvo de diversos estudos nas últimas décadas [20, 24-27]. Dessa maneira, por meio da análise bibliométrica, a avaliação de padrões e tendências das pesquisas realizadas sobre serapilheira representa uma oportunidade para o direcionamento de futuras pesquisas, objetivando estabelecer uma síntese do que já foi produzido e as perspectivas para direcionar pesquisadores e cientistas [28-31].

A análise bibliométrica, ou bibliometria, é um método de análise de metadados de forma qualiquantitativa que auxilia no entendimento de determinada área da ciência, com temas e métodos especificados durante a pesquisa, onde os resultados serão então analisados de acordo com uma escala temporal pré-estabelecida. Análises bibliométricas sobre a produção científica referente à serapilheira têm sido realizadas a nível mundial $[32,33]$. No entanto, os sites específicos de busca não representaram fielmente a situação do Brasil acerca do assunto, diante disso, objetivamos com esta pesquisa realizar uma abordagem quali-quantitativa da produção científica sobre serapilheira nos biomas e ecossistemas brasileiros nos últimos 12 anos (2008-2019).

\section{MATERIAL E MÉTODOS}

Foi realizado um levantamento quali-quantitativo de periódicos científicos indexados publicados de 2008 a 2019, referentes a trabalhos realizados no Brasil. O levantamento foi realizado na plataforma Periódico Capes (https://www.periodicos.capes.gov.br/), que envolve importantes bases de busca tais quais SciELO (https://www.scielo.org/), Web of Science (https://w,ww.webofknowledge.com/), além de outras bases de buscas que englobam periódicos 
nacionais e internacionais como Scopus, Google Acadêmico e Springer Link. O levantamento foi realizado pelas seguintes palavras-chave: "liteira", "serapilheira", "serrapilheira", "litter" e "litterfall", contidas no título, resumos ou nas palavras-chave de cada artigo (Figura 1).

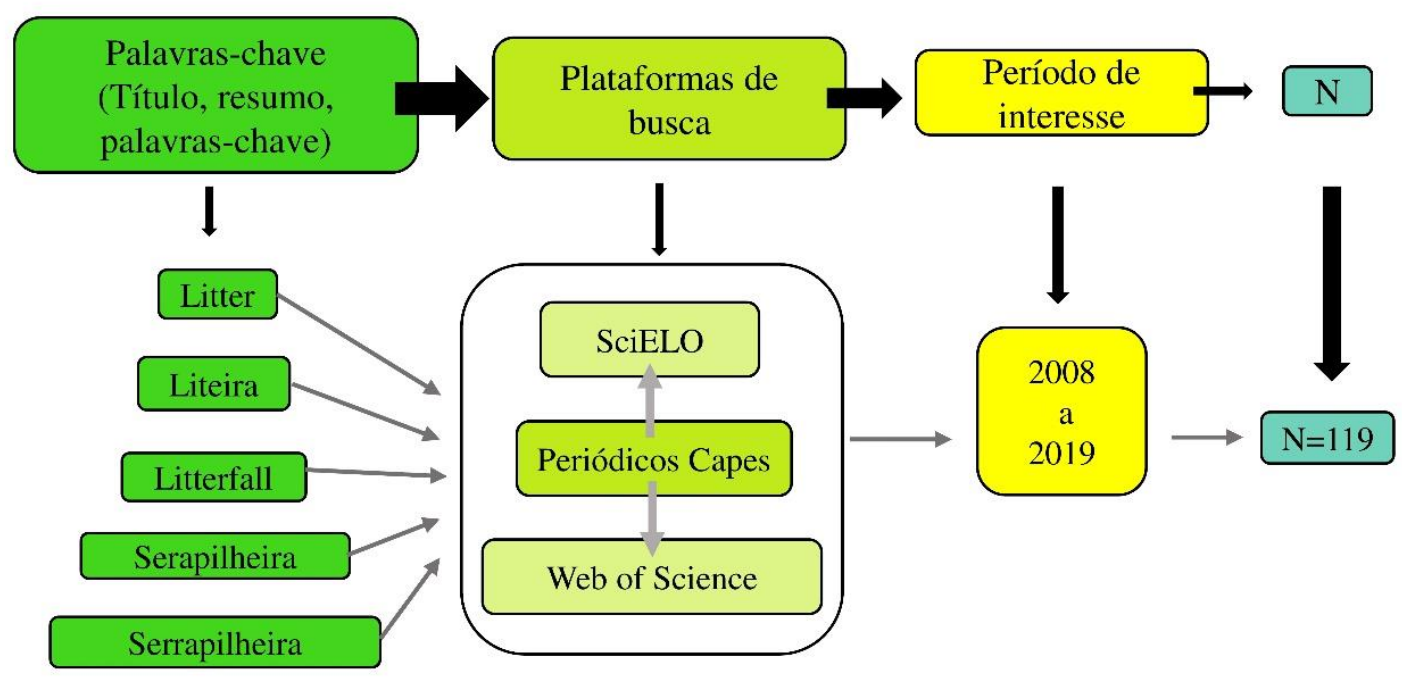

Figura 1 - Procedimentos e critérios estabelecidos para executar a análise bibliométrica sobre serapilheira no Brasil. $N$ = número total.

A análise quali-quantitativa foi realizada por meio das seguintes variáveis: 1) números de artigos publicados por ano; 2) lista das principais revistas cientificas que publicaram sobre o assunto; 3) estados brasileiros onde foi desenvolvido o estudo; 4) relação entre a quantidade de artigos pela extensão territorial de cada estado; 5) número de estudos desenvolvidos nos biomas brasileiros, classificados em Amazônia, Caatinga, Cerrado, Mata Atlântica, Pampa e Pantanal [34]; 6) número de estudos realizados em ecossistemas brasileiros, divididos em: floresta primária, floresta secundária, plantio misto, plantio mono específico, cerrado, pastagem, caatinga e transição; 7) relação do número de ecossistemas estudados pela extensão territorial de cada bioma brasileiro; e 8) quantidade média de estoque e aporte de serapilheira por biomas e ecossistemas.

Em relação às formações florestais brasileiras, alguns artigos apresentaram diferentes terminologias para um mesmo significado, por essa razão foram agrupados em: Floresta primária (termos encontrados: "floresta primária", "floresta nativa" e "mata de galeria"); Floresta secundária (termos encontrados: "secundária inicial", "secundária média", "secundária intermediária", "secundária tardia", "secundária avançada", "capoeira", "capoeirão" e "fragmento florestal alterado"); Cerrado (termos encontrados: "cerrado" e "cerrado stricto sensu") (Figura 2). 


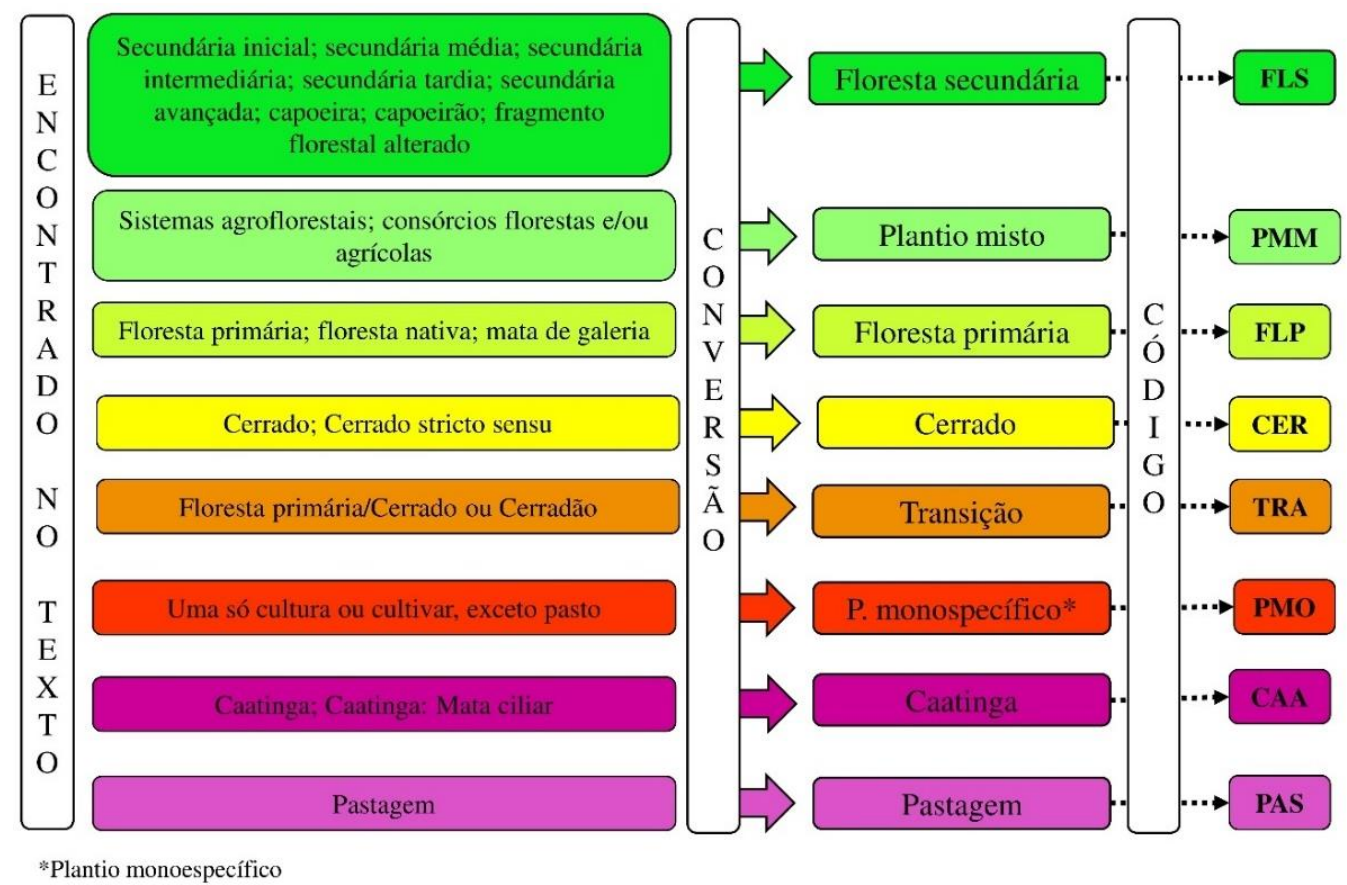

Figura 2 - Conversão de diferentes termos utilizados para um mesmo ecossistema e seus respectivos códigos.

Foi realizada a análise estatística básica e descritiva com os temas de levantamento e apresentados em histogramas, diagramas de Venn, mapa e tabelas. Os programas utilizados foram Microsoft ${ }^{\circledR}$ Office Excel versão 2016 e o software estatístico R versão 4.0.3 [35].

\section{RESULTADOS}

\subsection{Produção científica sobre o tema}

No período de 2008 a 2019, encontramos 119 artigos científicos relacionados à serapilheira, sendo que, o maior número de publicações foi encontrado em 2015 (15,13\%) e o menor em 2019 (5,04\%) (Figura 3). No intervalo 2014-2015 houve um aumento de $100 \%$ no número de publicações. A maior redução (45,46\%) ocorreu no intervalo de 2018 para 2019 (Figura 3).

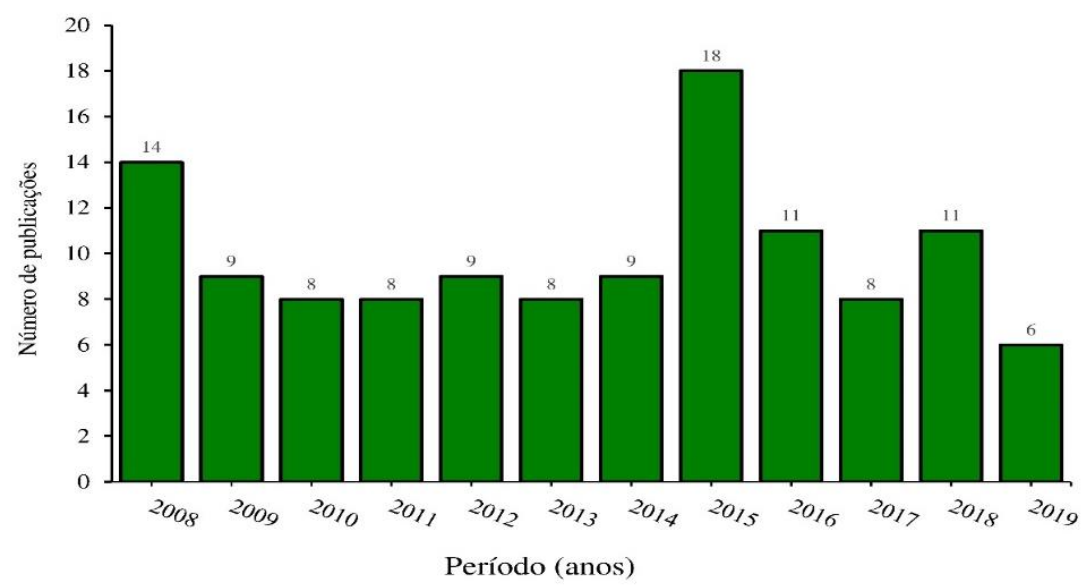

Figura 3 - Número absoluto de artigos científicos sobre serapilheira com estudos realizados no período de 2008 a 2019 no Brasil. 
No intervalo de 12 anos de avaliação, três revistas se destacaram em publicações, sendo elas: Revista Ciência Florestal (20,17\%), Revista Árvore (14,29\%) e Revista Floresta e Ambiente $(10,92 \%)$ (Figura 4).

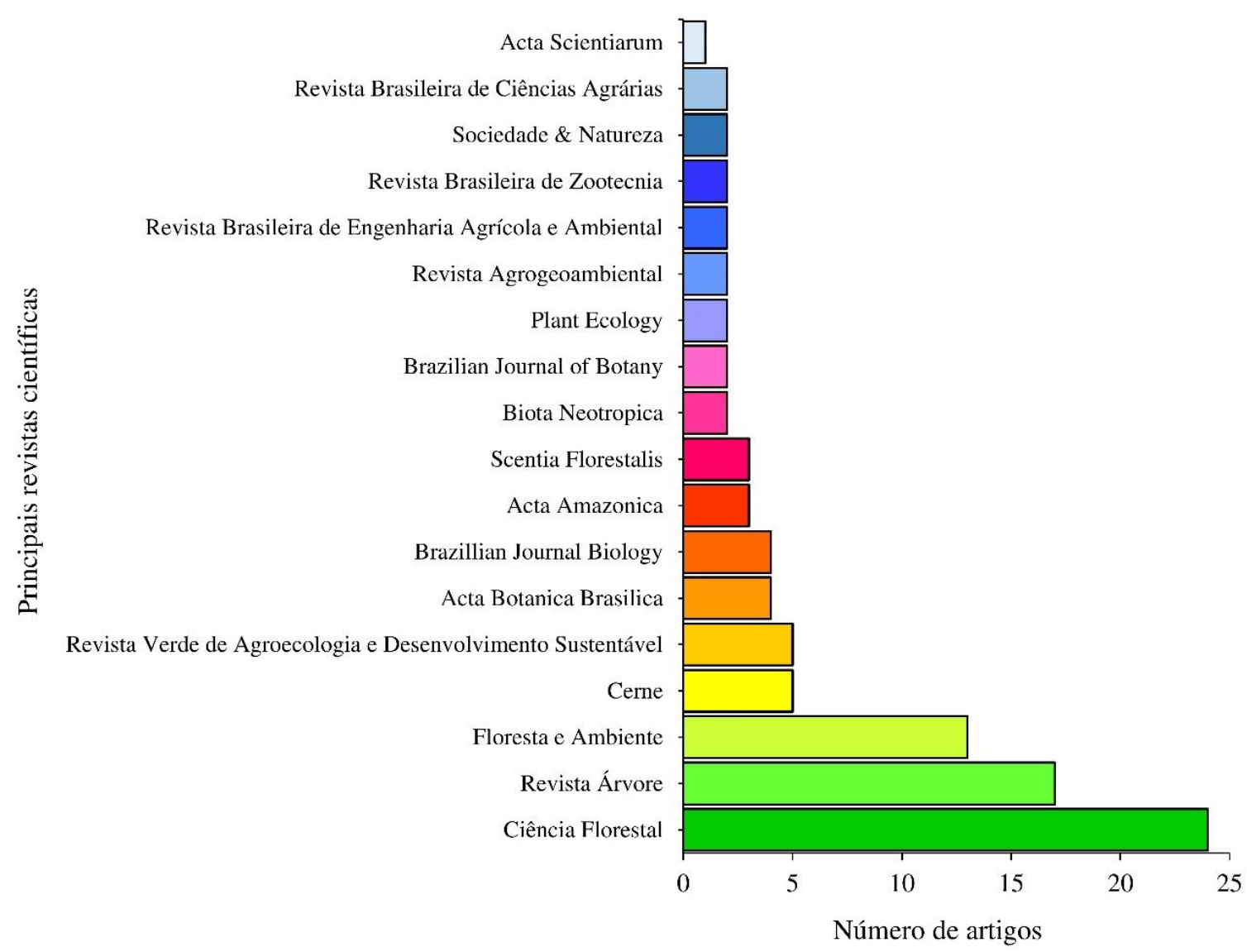

Figura 4 - Números de artigos publicados sobre o assunto serapilheira entre as principais revistas cientificas brasileiras, no período de 2008 a 2019.

\subsection{Distribuição da produção científica por estado brasileiro}

O Rio de Janeiro foi o estado com o maior número de estudos sobre serapilheira, sendo responsável por 13,45\% das publicações em todo o Brasil, seguido por Minas Gerais e Rio Grande do Sul, correspondendo a 11,76\% cada um (Figura 5A). Entretanto, sabendo da discrepância na extensão territorial dos estados brasileiros, a relação número de trabalhos por $\mathrm{km}^{2}$ faz-se necessária para diminuir os erros da equiparação. Deste modo, Rio de Janeiro continua com maior produção científica no Brasil, pois apresentou 16 publicações em $43.750,423 \mathrm{~km}^{2}$, o que equivale a 0,000366 artigos $\mathrm{km}^{-2}$ (Figura 5B). Em contrapartida, apesar de ter sido encontrado apenas dois artigos no Distrito Federal, a relação quantidade de artigos por $\mathrm{km}^{2}$ mostrou-se próxima a do Rio de Janeiro (Figura 5B). 


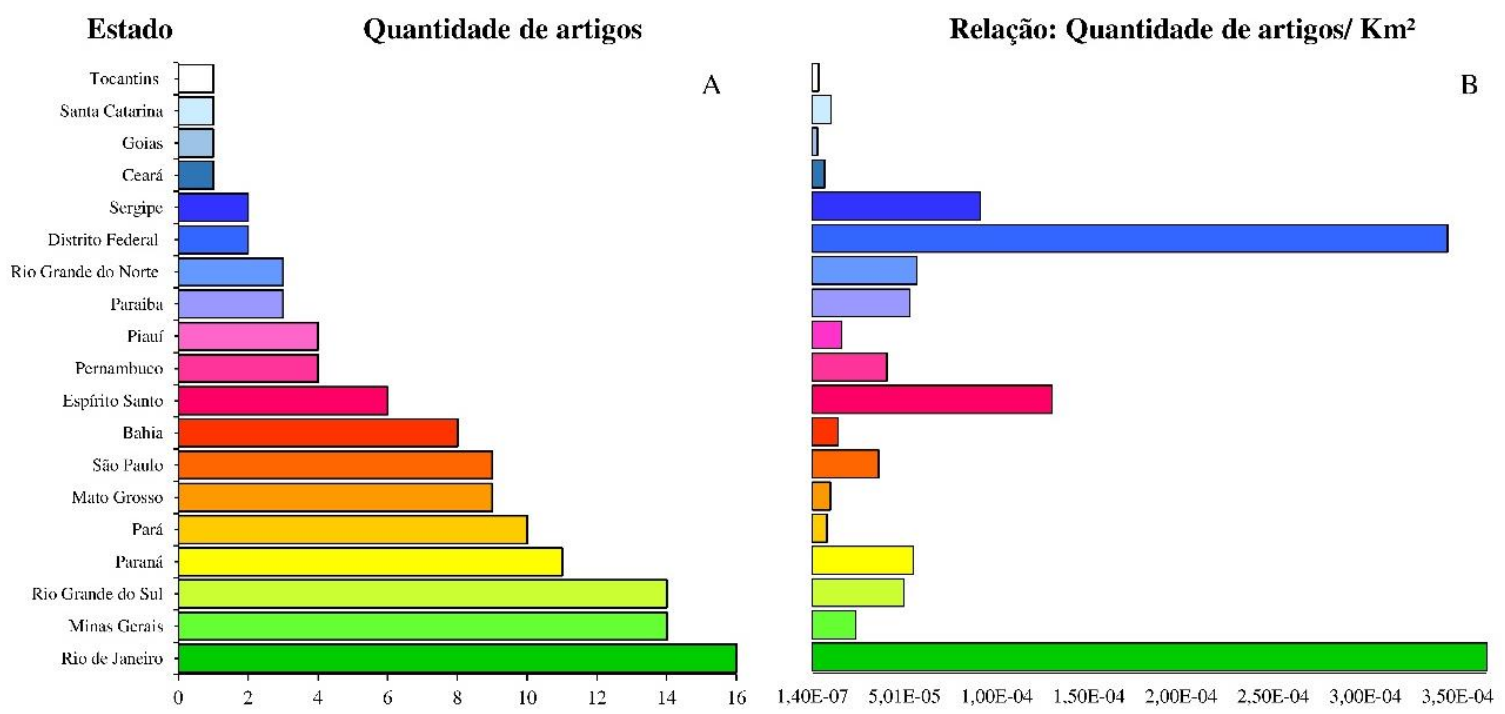

Figura 5 - A) Números de artigos publicados sobre serapilheira nos estados brasileiros, de 2008 a 2019 e; B) A relação da quantidade de artigos por $\mathrm{Km}^{2}$ de cada estado.

\subsection{Distribuição da produção cientifica por bioma}

Constatamos que as publicações se concentraram, principalmente, no bioma Mata Atlântica $(55,72 \%)$, seguida de Cerrado (14,74\%), Caatinga (12,82\%) e Amazônia (9,62\%) (Figura 6). Os demais biomas contribuíram com menos de $8 \%$.

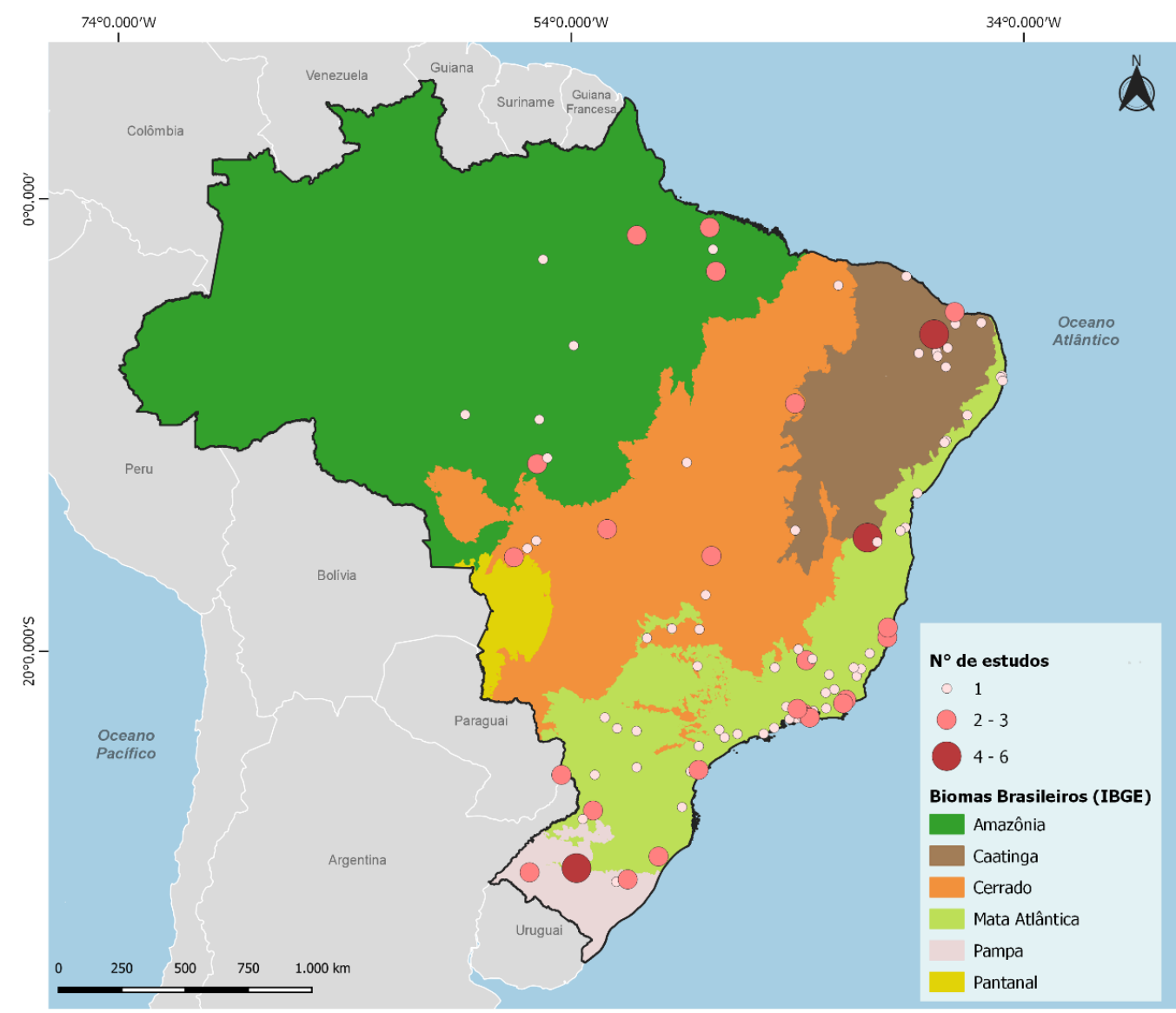

Figura 6 - Distribuição geográfica dos estudos realizados com aporte e estoque de serapilheira no Brasil, publicados de 2008 a 2019. 


\subsection{Aporte e estoque de serapilheira}

Dos 119 artigos analisados, $85(71,4 \%)$ foram sobre aporte, $26(21,9 \%)$ referente ao estoque e $8(6,7 \%)$ abordando ambos parâmetros (Figura 7A). Estes mesmos artigos avaliaram 235 ecossistemas, sendo $156(63,4 \%)$ com aporte, $59(25,1 \%)$ com o estoque e $20(6,7 \%)$ com ambos (Figura 7B).

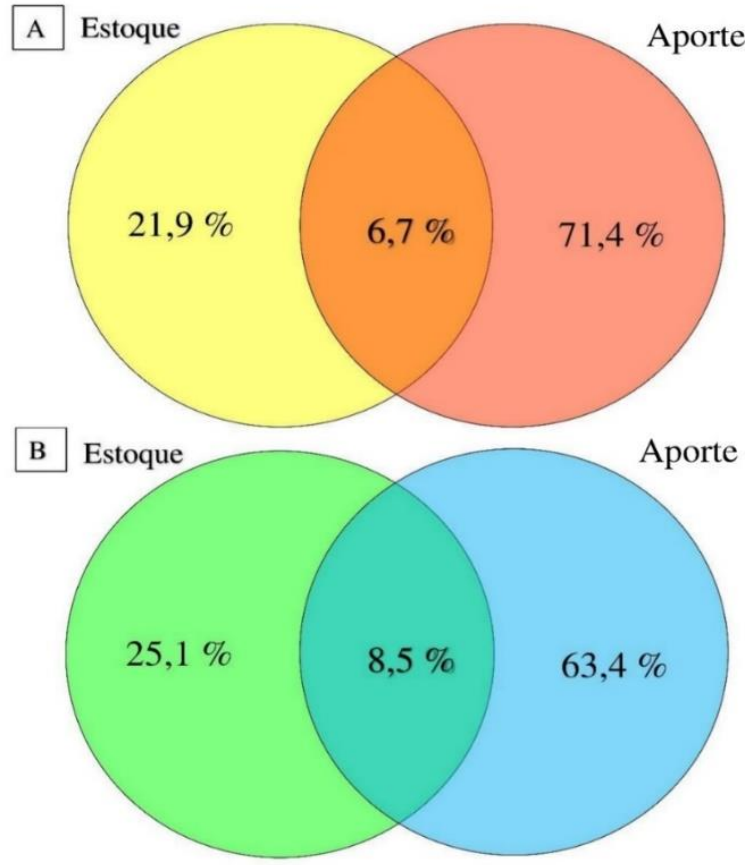

Figura 7 - A) Porcentagem de artigos que quantificaram o estoque elou aporte da serapilheira no período de 2008 a 2019; B) Porcentagem de ecossistemas que apresentaram análise de estoque elou aporte da serapilheira no período de 2008 a 2019.

No Cerrado e Amazônia foram encontradas a mesma quantidade de estudos (29), todavia, a relação do número de ecossistemas por km² é menor na Amazônia (Tabela 1). Já a Mata Atlântica apresenta o maior número de estudos dos ecossistemas existentes no bioma (Tabela 1).

Tabela 1 - Número de ecossistemas estudados e a relação com a área de cada bioma brasileiro.

\begin{tabular}{lccc}
\hline Biomas & $\begin{array}{c}\text { Área } \\
\left(\mathbf{k m}^{\mathbf{2}}\right)\end{array}$ & $\begin{array}{c}\text { Número de } \\
\text { Ecossistema }\end{array}$ & $\begin{array}{c}\text { Relação } \\
\text { Ecossistema por } \mathbf{k m}^{-2}\end{array}$ \\
\hline Amazônia & 4196943 & 29 & 0,000007 \\
Cerrado & 2036448 & 29 & 0,000014 \\
Mata Atlântica & 1110182 & 129 & 0,000116 \\
Caatinga & 844453 & 36 & 0,000043 \\
Pampa & 176496 & 6 & 0,000034 \\
Pantanal & 150355 & 6 & 0,000040 \\
\hline
\end{tabular}

\subsection{Meta-análise do aporte e estoque de serapilheira no Brasil}

Os maiores valores de estoque de serapilheira foram encontrados no Cerrado e na Caatinga, correspondendo a 7,24 $\pm 1,98 \mathrm{Mg} \mathrm{ha}^{-1}$ e 6,82 $\pm 4,49 \mathrm{Mg} \mathrm{ha}^{-1}$ respectivamente (Figura 8A), sendo 
ainda que, os biomas Caatinga e Mata atlântica apresentaram a maior variação dos resultados do estoque (Figura 8A). Para aporte, o bioma Amazônia apresentou maiores valores, correspondendo a 8,32 $\pm 2,57 \mathrm{Mg} \mathrm{ha}^{-1}$ ano ${ }^{-1}$ (Figura 8B). E os biomas com maior variação dos valores para aporte foi maior na Mata Atlântica e Cerrado (Figura 8B).

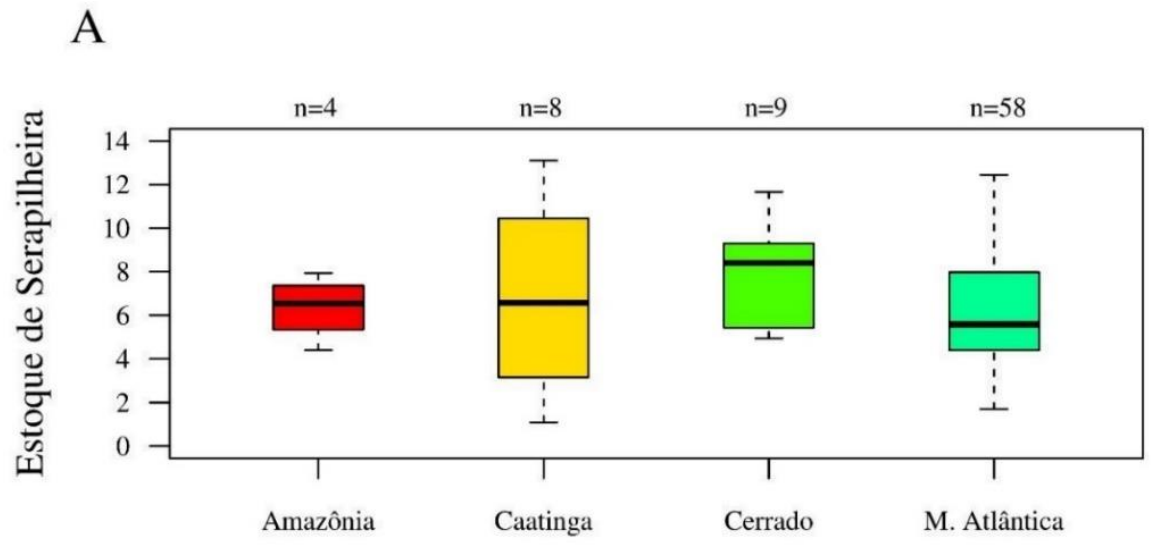

$\mathrm{B}$

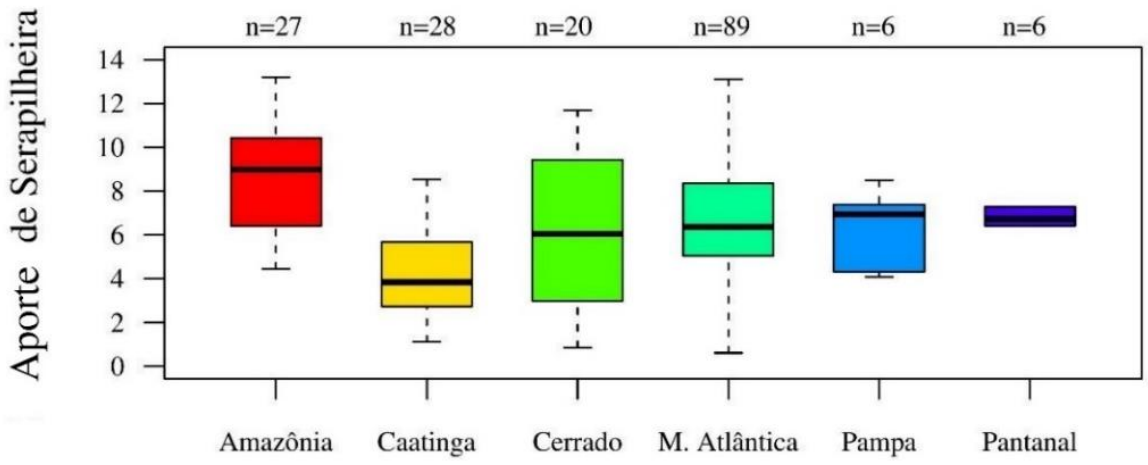

Biomas

Figura 8 - Quantidade de serapilheira por bioma brasileiro entre os estudos desenvolvidos de 2008 a 2019. A) Estoque e; B) Aporte; $n=$ número estudos para cada bioma.

\subsection{Quantidade média do estoque e aporte de serapilheira nos ecossistemas brasileiros}

Observamos que em mais da metade dos artigos encontrados ao longo dos 12 anos, os autores optaram por desenvolver suas pesquisas exclusivamente um ecossistema (Tabela 2). O restante $(48,74 \%)$ estudou mais de um ecossistema, sendo que, destes, em apenas $6,9 \%$ abordou cinco ou mais ecossistemas (Tabela 2).

Tabela 2 - Números de ecossistemas estudados simultaneamente por artigos sobre estoque e aporte de serapilheira no Brasil, no período de 2008 a 2019.

\begin{tabular}{cc}
\hline $\begin{array}{c}\text { Número de } \\
\text { artigos }\end{array}$ & $\begin{array}{c}\text { Número de ecossistemas estudados } \\
\text { simultaneamente em cada artigo }\end{array}$ \\
\hline 61 & 1 \\
23 & 2 \\
23 & 3 \\
8 & 4 \\
4 & $\geq 5$ \\
\hline
\end{tabular}


Em relação ao estoque e ao aporte de serapilheira nos ecossistemas estudados, três se destacaram pela quantidade de trabalhos encontrados tanto de estoque quanto de aporte de serapilheira, sendo eles FLS, PMM e PMO (Figura 9). No geral, o maior valor médio do estoque de serapilheira foi encontrado no plantio misto com a média de $8,58 \pm 3,16 \mathrm{Mg} \mathrm{ha}^{-1}$ (Figura 9A). Enquanto que, nos ecossistemas de pastagem foram observados os menores valores médios tanto para estoque $(2,35 \pm$ $\left.0,91 \mathrm{Mg} \mathrm{ha}^{-1}\right)$ (Figura 9A), quanto para aporte $\left(2,76 \pm 1,56 \mathrm{Mg} \mathrm{ha}^{-1}\right.$ ano $\left.^{-1}\right)$ (Figura 9B).

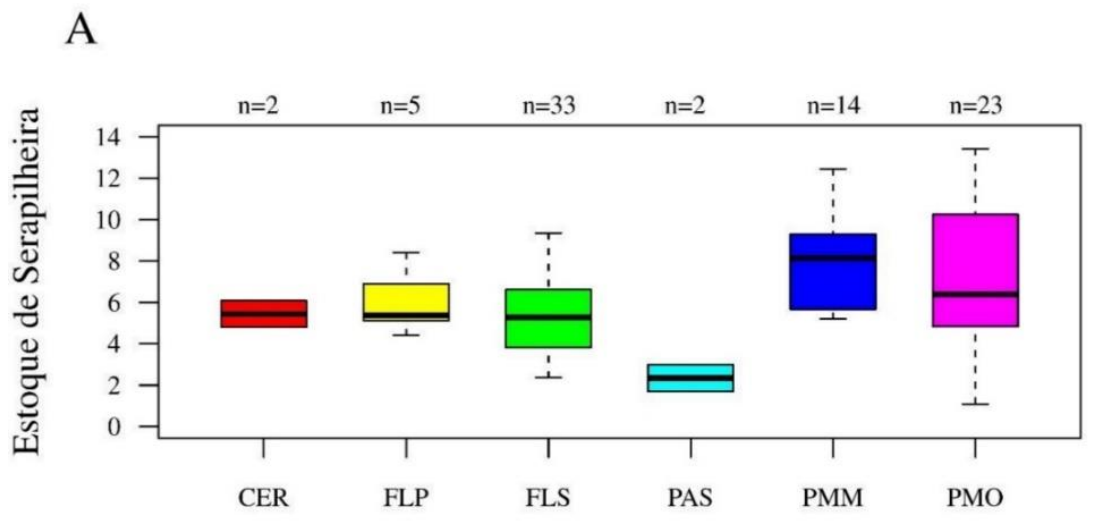

B

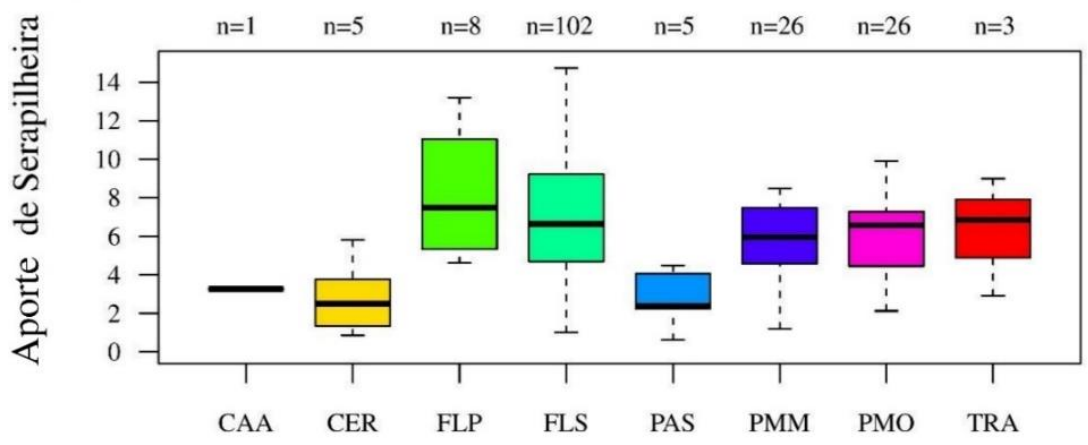

Ecossistemas

Figura 9 - Quantidade de serapilheira por ecossistemas brasileiros entre os estudos desenvolvidos de 2008 a 2019. A) Estoque B) Aporte. Onde: CAA= caatinga; $C E R=$ cerrado; $F L P=$ floresta primária; $F L S=$ floresta secundária; $P A S=$ pastagem $; P M M=$ plantio misto; $P M O=$ plantio monoespecífico; $T R A=$ transição Amazônia/Cerrado; e $n=$ número de ecossistemas levantados.

O maior aporte foi encontrado no FLP, com média de 8,19 $\pm 3,27 \mathrm{Mg} \mathrm{ha}^{-1}$ ano $^{-1}$ (Figura 9B). O ecossistema de floresta secundária foi o que apresentou a maior quantidade de trabalhos para os dois estudos (Figura 9). Percebeu-se também que o valor médio do estoque de serapilheira é maior no PMM, quando comparado ao PMO (Figura 9A). Entretanto, a aporte do PMO é maior do que a do PMM (Figura 9B).

\section{DISCUSSÃO}

\subsection{Produção científica sobre o tema}

O número de estudos sobre serapilheira ao longo dos anos é possivelmente um reflexo dos investimentos de recursos na ciência brasileira. Isso porque a necessidade de instalação e acompanhamento de experimentos a médio e longo prazo, aliado ao período de avaliação das revistas para a correção e publicação de artigos científicos (que geralmente ultrapassam um ano 
para revistas brasileiras), fazem com que, os resultados desses investimentos apareçam nos anos posteriores.

Como exemplo disso, percebeu-se que, em 2014 houveram os maiores investimentos e auxílios à pesquisa científica registrados no Brasil até o ano de 2018 [36]. Isso resultou no maior número de publicações em 2015, o que contribuiu com 15,16\% das publicações desenvolvidas ao longo dos 12 anos (Figura 3). A relação direta da produção científica brasileira com os investimentos demonstra a necessidade constante da aplicação de recursos financeiros nessa área da ciência. Assim, haverá o aumento dos estudos relacionados à serapilheira, e consequentemente, maior contribuição para o entendimento da manutenção dos ecossistemas florestais. A continuidade desses estudos colaborará com o avanço de práticas eficazes para a restauração de áreas degradadas, buscando a interdisciplinaridade e enfatizando o retorno dos serviços ecossistêmicos [37]. No período de estudo, os artigos sobre serapilheira foram voltados, principalmente, à avaliação nutricional, ou seja, a contribuição da serapilheira como via de entrada nutrientes para o solo [3841], à utilização como indicador de recuperação de áreas degradadas [42-44], à possível correlação com a sazonalidade [45-47] e a sua quantificação em plantios monoespecíficos, como por exemplo os de Eucalyptus spp. [48-50] para o entendimento sobre a necessidade de aplicação de insumos químicos para manutenção da produtividade.

As publicações voltadas ao estudo da serapilheira como indicador de sustentabilidade e de restauração florestal tem se destacado nos últimos anos, principalmente, pelo fato de que as atividades econômicas mais desenvolvidas no Brasil, como a pecuária, o agronegócio e a mineração, degradam ou alteram os ecossistemas naturais [51-53]. Neste sentido, para restauração destes ecossistemas, o monitoramento por meio da avaliação da serapilheira é uma etapa fundamental e indispensável para entender como a trajetória de restauração está ocorrendo [54]. Consubstancialmente, o comprometimento do Brasil no acordo de Paris em garantir, até 2030, a inexistência do desmatamento ilegal, revela a maior necessidade sobre estudos com o tema, principalmente pelo fato de que, a quali-quantificação da serapilheira demonstra o nível de conservação ou restauração ecológica de ecossistemas florestais e a sua relação com as alterações abióticas, como precipitação pluviométrica, intensidade e direção dos ventos, radiação e temperatura [55].

\subsection{Distribuição da produção científica por estado brasileiro}

A distribuição desigual da produção científica sobre o tema serapilheira nos diferentes estados brasileiros pode ser explicada pela condição socioeconômica diretamente relacionada às limitações ao acesso à internet e o baixo número de pessoas com ensino superior completo. No caso do Amazonas, estado com maior extensão territorial do Brasil, 28,8\% da população não tem acesso à internet e apenas $14,8 \%$ da população com idade superior a 25 anos possui ensino superior completo [56]. Aliado a isso, apesar das regiões Norte e Nordeste, juntas, apresentarem mais do que o triplo de Fundações de Apoio à Pesquisa (FAPs), a concentração das melhores e mais antigas fundações na região Sudeste, tais quais FAPESP, FAPERJ e FAPEMIG contribuem para esta disparidade [57].

A extensão de áreas urbanizadas também mostrou relação com a produção científica voltada à serapilheira entre os estados. A exemplo disso, o baixo índice de publicação sobre serapilheira em São Paulo, chama atenção, pois o estado apresenta maior área urbanizada do Brasil [58] e dispõe da terceira instituição que mais investe em pesquisa científica no país - Fundação de Amparo à Pesquisa do Estado de São Paulo (FAPESP). Entretanto, incentiva as pesquisas voltadas aos problemas urbanos. Outrossim, as três maiores universidades do estado de São Paulo e, consequentemente, as que mais realizam pesquisas científicas, tem o foco voltado as pesquisas médicas [59].

Os investimentos do governo em pesquisa científica, por sua vez, são essenciais para que haja um bom índice de publicações e consequentemente descobertas e o entendimento da sociedade sobre a importância de um tema. O estado do Rio de Janeiro foi o que apresentou o maior número de artigos (Figura 5A), provavelmente o que pode ter relação com o Museu Nacional e a Escola Nacional de Botânica tropical criada mais recentemente, além de estar inserido no bioma Mata Atlântica, onde as pesquisas científicas voltadas aos serviços ecossistêmicos recebem 
financiamento massivo do governo. Ademais, a FAPERJ (Fundação de Amparo à Pesquisa do Estado do Rio de Janeiro) está entre os 5 órgãos que mais financiaram a pesquisa no Brasil [36].

Apesar do Rio de Janeiro apresentar o maior número de publicações no país, o Distrito Federal, com apenas 2 publicações, apresentou uma relação de artigos por $\mathrm{km}^{2}$ próxima ao do Rio de Janeiro (Figura 5B). Essa relação revela a necessidade de haver uma quantidade de estudos proporcional à área do estado, visto que, assim, pode-se obter informações que representem com menor margem de erro possível toda sua extensão.

Outro ponto que deve ser levado em consideração na distribuição das publicações por estado são as características peculiares e aptidão produtiva. Como exemplo, no Rio de Janeiro, tem se destacado publicações em áreas degradadas [55, 60, 61]. Rio Grande do Sul está localizado na região que possui a maior área de plantio de Pinus do Brasil [62, 63], por isso, vários trabalhos vêm sendo desenvolvidos sobre a serapilheira nestes povoamentos [50, 64-67]. No estado do Pará, por sua vez, a maioria dos trabalhos verificam o efeito da sazonalidade no aporte de serapilheira [46, $47,68,69]$.

\subsection{Distribuição da produção por bioma}

Verificou-se uma relação direta entre a quantidade de artigos científicos e a porcentagem de desmatamento nos biomas. Isso é observado principalmente na Mata Atlântica, com $28 \%$ de sua vegetação original [70] e possui a maior quantidade de artigos publicados. Essa relação também pode ser explicada pelo elevado incentivo a pesquisas e pela grande quantidade de pós-graduações em locais os quais posteriormente serão induzidas ao processo de restauração florestal [71].

$\mathrm{Na}$ Mata Atlântica, a quantidade elevada de estudos em relação aos outros biomas também pode ser justificada pela real necessidade de converter os impactos ambientais negativos causados pela destruição dos seus ecossistemas, revertendo a ameaça de extinção do bioma [72]. Para isso, desde 2006, medidas legais estão sendo criadas para atingir esse objetivo, como o artigo 36 da Lei 11.428 de 2006 (Lei Mata Atlântica) que institui um fundo de restauração para o bioma, o qual segundo o art. 38 da mesma lei beneficia com recursos os projetos que envolvam pesquisa científica na Mata Atlântica. Por essa razão, as pesquisas são voltadas, principalmente, ao potencial de produção de serapilheira pelas árvores como um indicador de recuperação de áreas [60, 61, 73].

Em contrapartida, nos biomas Pantanal e Pampa o número de artigos é inferior aos demais biomas, pois não apresentam predominância de áreas florestais. Por esse motivo, a maioria das publicações ocorre em ecossistemas de transição entre biomas (Figura 6). No Pantanal os estudos geralmente são voltados aos problemas recorrentes no bioma, tais quais a contaminação dos cursos d'água por meio do despejo inadequado de agroquímicos [74] e ultimamente, incêndios descontrolados. Somado a isso, a topografia e as inundações características da região podem dificultar as avaliações periódicas necessárias para o estudo da serapilheira, além de tornar indispensável a adaptação nos procedimentos de campo, como a escolha do formato dos coletores de aporte e a altura em que estes serão alocados do chão [75, 76], o que além de dificultar o transporte dos coletores em campo, pode tornar a pesquisa mais onerosa.

Do total de área da Amazônia brasileira, 20\% já foram desmatados, o equivalente a 1 milhão de $\mathrm{km}^{2}$, com registros de incremento de $29,5 \%$ de 2018 a 2019 [77]. Logo, esperamos que o número de pesquisas aumente, tendo em vista o desmatamento desenfreado e a necessidade de restauração devido à importância socioeconômica. Além disso, percebemos que a maioria dos estudos do bioma Amazônia estão localizadas em unidades de conservação $[47,78]$ e uma fração menor em áreas anteriormente degradadas pela mineração, atividade com intenso impacto econômico na região [54, 79]. No entanto, ainda é perceptível a insuficiência do número de publicações em função da extensão territorial da Amazônia. Um dos motivos desse problema é a baixa quantidade de programas de pós-graduação voltadas a Ciências Florestais, Botânica e áreas afins [80]. Outra explicação, tendo em vista a significativa contribuição das instituições públicas para a pesquisa científica, é a ausência de instituições de ensino superior (IES) com nota máxima no Índice Geral de Cursos (IGC), o qual é avaliado e divulgado anualmente pelo MEC, e tem como objetivo fornecer informações sobre a qualidade dos cursos de graduação e pós-graduação em determinada IES [81]. 
A escassez de pós-graduações, além de prejudicar o desenvolvimento de novas pesquisas, resulta no baixo número de profissionais qualificados para atuar em pesquisas, já que, dos 224 programas de pós-graduação em Ciências Agrárias existentes no Brasil, apenas 28 são referentes à área básica de Recursos Florestais [80] e esse número vem diminuindo gradativamente. Na Amazônia, esses números são ainda mais alarmantes, pois do total de programas de pós-graduação em Recursos Florestais, apenas 4 são encontrados no bioma [80]. Nesse sentido, inúmeras são as implicações para o país, pois até 2018, tinha-se 7,83 milhões de hectares de plantios florestais [63], logo, é necessário haver estudos que comprovem a manutenção e eficiência dos serviços ambientais originados por esses povoamentos, sobretudo na Amazônia onde os índices de desmatamento vêm aumentando demasiadamente.

\subsection{Aporte e estoque de serapilheira}

O maior número de estudos sobre o aporte de serapilheira ocorreu por meio do monitoramento dessa variável como indicador dos processos funcionais da comunidade florestal, além de observar as características adaptativas após impactos antrópicos ou naturais que ocorreram em determinado ecossistema [76, 82, 83]. O aporte destaca-se como um eficaz indicador de restauração florestal pois está diretamente relacionado à Produtividade Primária Líquida (PPL) da floresta [84]. As avaliações periódicas do aporte de serapilheira permitem prever possíveis mudanças nos processos ecológicos do ecossistema, e dessa maneira, auxiliam nas estratégias que devem ser adotadas para otimizar a restauração florestal, por exemplo [85]. Além disso, ao contrário da avaliação do estoque, o aporte permite um diagnóstico e uma análise mais completa das características ecossistêmicas, já que ocorrem em intervalos de tempo pré-determinado, o que também explica o maior número de trabalhos que utilizou este método de avaliação. Portanto, é possível verificar em quais épocas do ano o ecossistema aumenta a entrada de nutrientes por meio da serapilheira ou como a sazonalidade interfere na PPL [86].

Por outro lado, a avaliação do estoque de serapilheira é indispensável, tendo em vista os benefícios garantidos por esta variável na manutenção na disponibilidade de nutrientes no sistema solo-planta [87, 88], aumento da capacidade de retenção hídrica do solo, controle da umidade e da temperatura edáfica, e estímulo à emergência de plântulas. Somado a isso, a avaliação de seu conteúdo nutricional possibilita estimar as reservas de nutrientes do ecossistema florestal [89] e pode ser correlacionada às características do solo, composição da fauna edáfica e, principalmente, teor de lignina e carbono (qualidade da serapilheira) [90].

$\mathrm{O}$ aporte de serapilheira também pode ser relacionado a outros aspectos dos ecossistemas como a fenologia das espécies, composição florística, taxas de cobertura da floresta, DAP e efeitos da sazonalidade [33, 91, 92]. Sendo assim, estudos que abordam tanto o aporte quanto o estoque de serapilheira são capazes de indicar, com mais confiabilidade, os processos funcionais que mantém os ecossistemas, além de estabelecerem valores de referência para o ecossistema estudado.

A insuficiência de estudos nos biomas brasileiros gera uma análise superficial, principalmente para os que possuem as menores relações dos ecossistemas estudados por $\mathrm{km}^{2}$. Para reverter essa situação, o incentivo financeiro à pesquisa na área de ciências agrárias torna-se uma medida essencial, somado à melhor distribuição dos cursos de pós-graduação no país. Além disso, é interessante que seja realizada a identificação prévia dos ecossistemas existentes dentro dos biomas e posteriormente, a instalação de experimentos para obtenção de dados sobre aporte e estoque de serapilheira. Os benefícios desse monitoramento de dados atingem desde o pequeno agricultor ao grande produtor rural, além das empresas que são obrigadas a restaurar as áreas degradadas oriundas de suas atividades. Para o país, o melhor desempenho das plantações acarretará em mais exportações, ou seja, avanços econômicos.

\subsection{Meta-análise do aporte e estoque de serapilheira no Brasil}

A avaliação do estoque e aporte de serapilheira no período estudado permite quantificar a variabilidade que ocorre em cada bioma, servindo como parâmetro para os demais trabalhos desenvolvidos no país, principalmente aqueles que apresentam um número representativo de 
estudos. O elevado intemperismo e a baixa disponibilidade de nutrientes dos solos da Amazônia fazem com que a produtividade da vegetação dependa do material vegetal na superfície e eficiente ciclagem de nutrientes [54], sendo o tema de extrema relevância para estudos de sustentabilidade de ecossistemas florestais. Na Caatinga, por sua vez, a principal função da serapilheira estocada no solo é a proteção, não ocorrendo uma rápida decomposição, pois os índices pluviométricos não são intensos e constantes como na Amazônia [93].

O tipo de vegetação predominante em cada bioma também influencia diretamente na formação da camada vegetal depositada sobre o solo. A elevada variação tanto no estoque quanto no aporte de serapilheira na Mata Atlântica é reflexo direto dos cinco tipos de florestas existente nesse bioma [94], onde cada um possui características peculiares de aporte. No Pampa, a baixa variação é decorrente de apenas 5,38\% do território possuir vegetação florestal [95] e o maior aporte de serapilheira ocorre em dois períodos do ano, primavera e verão [96].

A média dos valores encontrados para estoque e aporte de serapilheira, permite adotar valores de referência para os biomas estudados. Entretanto, biomas como Amazônia, Caatinga, Cerrado e Pantanal necessitam de mais pesquisas, para um melhor entendimento do padrão de aporte e estoque de serapilheira. Na Caatinga, por exemplo, houve uma elevada variabilidade dos resultados do estoque, com desvio padrão de $\pm 4,49 \mathrm{Mg} \mathrm{ha}^{-1}$ em relação à média, retrato do número limitado de estudos publicados no período (Figura 8A). Além disso, esses trabalhos foram concentrados em sua totalidade no Norte e, principalmente, nordeste do bioma (Figura 6). Com isso, a distribuição espacial influencia uma possível extrapolação para padrões de estoque no bioma.

\subsection{Quantidade média do estoque e aporte de serapilheira nos ecossistemas brasileiros}

O maior número de estudos que avalia apenas um ecossistema pode estar relacionado à dificuldade de locomoção ou acesso a várias áreas, que torna a pesquisa mais dispendiosa. Por isso, visam quantificar o estoque, o aporte, os nutrientes e/ou a decomposição da serapilheira no ecossistema [41, 96, 97]. Já a maioria dos artigos que abordam mais de um ecossistema possui o objetivo de avaliar a magnitude diferencial do ciclo biogeoquímico em diferentes ecossistemas e entender o porquê ocorreu essa maior ou menor eficiência de serapilheira e nutrientes $[49,98]$.

De maneira geral, as florestas secundárias ocorrem como parte dos processos ecológicos advindos de distúrbios naturais ou antrópicos. Entretanto, a utilização desenfreada dos recursos naturais com a exploração madeireira ilegal, expansão das áreas de pastagens e aumento das áreas utilizadas pela atividade minerária, por exemplo, intensificam a destruição da formação vegetal original [99]. Sendo assim, as florestas secundárias estão distribuídas por todo o país e merecem atenção pelas importantes funções ecológicas desempenhadas, como a manutenção do fluxo genético, conservação de ciclos biogeoquímicos e o elevado acúmulo de biomassa e nutrientes [100]. Em decorrência da importância das florestas secundárias, justifica-se a elevada quantidade de publicações nesse ecossistema e a baixa produção científica no ecossistema de floresta primária (FLP).

A elevada variabilidade encontrada nos valores médios de estoque e aporte no ecossistema de floresta secundária (FLS) ocorre, além da influência dos fatores bióticos e abióticos, pelo histórico de utilização da área. O processo de sucessão florestal, após utilização do fogo, por exemplo, resulta inicialmente na diminuição da diversidade de espécies [101], onde apenas as mais adaptadas a essas condições edafoclimáticas se estabelecem e desenvolvem [102]. Somado a isso, a elevada quantidade de trabalhos nesses ecossistemas permite que os valores médios estimados para aporte e estoque de serapilheira das florestas secundárias no Brasil sirvam como referência para trabalhos posteriores, que objetivam o monitoramento ou a comparação dessas variáveis.

Assim como as florestas secundárias, a elevada quantidade de publicações nos plantios florestais (mono específicos e misto) ocorre em função do crescimento constante da silvicultura brasileira (IBÁ, 2019). Como benefícios desse crescimento, diminui-se teoricamente, o alívio das pressões sobre os ecossistemas de florestas naturais [100].

Das culturas abordadas nos artigos, as mais estudadas são: a) Tectona grandis Linn. F. [103], b) Acacia auriculiformis A. Cunn. ex Benth., c) Mimosa caesalpiniifolia Benth. [60], d) Pinus taeda L. [64, 66] e f) Eucalyptus sp. e híbridos [49, 50, 65, 96]. Destas, as duas últimas espécies são as 
que possuem maior quantidade de estudos no Brasil, em razão do grande potencial econômico para o país [63].

\section{CONCLUSÃO}

Pela análise bibliométrica, demostramos que as publicações cientificas no Brasil referente à serapilheira apresentam instabilidade e seus maiores registros estiveram diretamente relacionadas aos investimentos e auxílios a pesquisa. Ressaltamos a importância da valorização dos núcleos de pesquisas das universidades para a manutenção das pesquisas, bem como a necessidade de investimentos na ciência florestal brasileira para a conservação dos biomas. A maioria dos estudos foi realizada no estado do Rio de Janeiro (bioma Mata atlântica) e no ecossistema floresta secundária, explicado pela alta porcentagem de desmatamento, incentivo financeiro à recuperação florestal e a presença das Fundações de Amparo à Pesquisa que mais investem em pesquisa no Brasil.

Evidenciamos pelos resultados da meta-análise que a maioria dos artigos avaliou o aporte de serapilheira. Dentre os biomas, a Amazônia apresentou os maiores valores médios para este método, enquanto que, para ecossistemas, isso foi observado para floresta primária, em razão da grande diversidade de espécies, maior preservação e conservação florestal. Para estoque de serapilheira, o bioma Cerrado e os ecossistemas de plantio monoespecífico e misto, evidenciaram os maiores valores. Neste contexto, com base nos artigos analisados, presumimos um aumento dos estudos de serapilheira nos ecossistemas de plantio monoespecífico e misto, devido sua importância ecológica e econômica para o Brasil.

\section{AGRADECIMENTOS}

Ao Conselho Nacional de Pesquisa Científica (CNPq) e ao Laboratório de Manejo de Ecossistemas e Bacias Hidrográficas da Universidade Federal Rural da Amazônia (UFRA), pelo apoio à pesquisa científica.

\section{REFERÊNCIAS BIBLIOGRÁFICAS}

1. IBRAM, Instituto Brasileiro de Mineração. Presidente do IBRAM avalia 2019 e fala sobre perspectivas para 2020 [Internet]. 20 dez 2019 [citado em 1 jan 2020]. Disponível em: https://ibram.org.br/noticia/presidente-do-ibram-avalia-2019-e-fala-sobre-perspectivas-para-2020/

2. IPEA, Instituto de Pesquisa Econômica Aplicada. PIB Agropecuário deve crescer 0,5\% em 2019 e $2 \%$ em 2020 [Internet]. 20 ago 2019 [citado em $12 \mathrm{dez}$ 2020]. Disponível em: https://www.ipea.gov.br/portal/index.php?option=com_content\&view=article\&id=34980

3. Angelo JA, Oliveira MDM, Ghobril CN. Balança comercial dos agronegócios paulista e brasileiro de 2019. IEA, Instituto de Economia Agrícola [Internet]. 22 jan 2020. Disponível em: http://www.iea.agricultura.sp.gov.br/out/TerTexto.php?codTexto=14751

4. Weisse M, Petersen R. Brasil e Indonésia têm dificuldades para diminuir desmatamento. WRI, World Resources Institute [Internet]. 2015 [citado em 1 jan 2020]. Disponível em: https://www.wri.org/blog/2015/09/brasil-e-indonesia-tem-dificuldades-para-diminuir-desmatamento

5. McGrath M. Brasil liderou desmatamento de florestas primárias no mundo em 2018, mostra relatório. BBC, British Broadcasting Corporation [Internet]. 25 abr 2019 [citado em 1 jan 2020]. Disponível em: https://www.bbc.com/portuguese/geral-48046107

6. Benedek Z, Fertő I. Does economic growth influence forestry trends? An environmental Kuznets curve approach based on a composite Forest Recovery Index. Ecol Indic. 2020 May;112:9, doi: 10.1016/j.ecolind.2020.106067

7. Bomfim B, Silva LCR, Pereira RS, Gatto A, Emmert F, Higuchi N. Litter and soil biogeochemical parameters as indicators of sustainable logging in Central Amazonia. Sci Total Environ. 2020 Apr;714:1-9, doi: 10.1016/j.scitotenv.2020.136780

8. Machado MR, Sampaio PDTB, Ferraz J, Camara R, Pereira MG. Nutrient retranslocation in forest species in the Brazilian Amazon. Acta Sci. 2016 Jan;38(1):93-101, doi: 10.4025/actasciagron.v38i1.26805 
9. Vivanco L, Austin AT. The importance of macro- and micro-nutrients over climate for leaf litter decomposition and nutrient release in Patagonian temperate forests. Forest Ecol Manag. 2019 Jun;441:144-54, doi: 10.1016/j.foreco.2019.03.019

10. Mangenot F. Les litières forestières: signification écologique et pédologique. Rev Française. 1980 Dec;32(4):339, doi: 10.4267/2042/21417

11. Caldeira MVW, Godinho TO, Moreira FL, Campanharo ÍF, Castro KC, de Mendonça AR, et al. Litter as an ecological indicator of forest restoration processes in a dense ombrophylous lowland forest. Floresta e Ambient. 2019;26(1):1-11, doi: 10.1590/2179-8087.041118

12. Inkotte J, Martins RCC, Scardua FP, Pereira RS. Métodos de avaliação da ciclagem de nutrientes no bioma Cerrado: uma revisão sistemática. Ci Florest. 2019;29(2):989-1003, doi: 10.5902/1980509827982

13. Lima Júnior PH, Ferreira WC, Dias DP, Côrrea RS, Silva DFP. Crescimento inicial de espécies arbóreas nativas em diferentes espaçamentos em área degradada. Global Sci Techn. 2019;12(1):183-96.

14. Frouz J. Effects of soil macro- and mesofauna on litter decomposition and soil organic matter stabilization. Geoderma. 2018;332:161-72, doi: 10.1016/j.geoderma.2017.08.039

15. Nakatsuka H, Karasawa T, Ohkura T, Wagai R. Soil faunal effect on plant litter decomposition in mineral soil examined by two in-situ approaches: Sequential density-size fractionation and micromorphology. Geoderma. 2020;357:113910, doi: 10.1016/j.geoderma.2019.113910

16. Scoriza RN, Pereira MG, Pereira GHA, Machado DL, Silva EMR. Métodos para coleta e análise de serrapilheira aplicados à ciclagem de nutrientes. Floresta e Ambient. 2012;2(2):01-18.

17. Queiroz MG, da Silva TGF, Zolnier S, de Souza CAA, de Souza LSB, Neto S, et al. Seasonal patterns of deposition litterfall in a seasonal dry tropical forest. Agric For Meteorol. 2019;279:107712, doi: 10.1016/j.agrformet.2019.107712

18. Guo Y, Chen HYH, Mallik AU, Wang B, Li D, Xiang W, et al. Predominance of abiotic drivers in the relationship between species diversity and litterfall production in a tropical karst seasonal rainforest. For Ecol Manage. 2019;449:117452, doi: 10.1016/j.foreco.2019.117452

19. Rani V, Sreelekshmi S, Preethy CM, BijoyNandan S. Phenology and litterfall dynamics structuring Ecosystem productivity in a tropical mangrove stand on South West coast of India. Reg Stu Mar Sci. 2016;8:400-7, doi: 10.1016/j.rsma.2016.02.008

20. Carvalho HCS, Ferreira JLS, Calil FN, e Silva-Neto CDM. Estoque de nutrientes na serapilheira acumulada em quatro tipos de vegetação no Cerrado em Goiás, Brasil. Rev Ecol Nutr Florest - ENFLO. 2019 May;7:e06, doi: 10.5902/2316980X37296

21. López CVC, Brienza Júnior S, Leão NVM, Ferreira AR, Rosa EPA, dos Santos IA. Fenologia de espécies da floresta secundária potencialmente acumuladoras de fósforo. In: Anais do IV Congresso Brasileiro de Sistemas Agroflorestais; Ilhéus (BA). Brasília (DF): Embrapa Amazônia Oriental; 2002.

22. Linger E, Hogan JA, Cao M, Zhang WF, Yang XF, Hu YH. Precipitation influences on the net primary productivity of a tropical seasonal rainforest in Southwest China: A 9-year case study. Forest Ecol Manag. 2020;467:118153, doi: 10.1016/j.foreco.2020.118153

23. Pereira DN, Martins WBR, Andrade VMS, Oliveira FA. Influência da remoção de serapilheira no teor de fósforo e potássio na Amazônia Oriental. Braz J Agric Sci. 2017 Sep;12(3):380-5, doi: 10.5039/agraria.v12i3a5458

24. Gomes LEO, Vescovi LC, Bernardino AF. The collapse of mangrove litterfall production following a climate-related forest loss in Brazil. Mar Pollut Bull. 2021;162:111910, doi: 10.1016/j.marpolbul.2020.111910

25. Smith DM, Larson BC, Kelty MJ, Ashton PMS. Stand dynamics: The ecology of forest succession. In: Ashton MS, Kelty MJ, editors. The pratice of silviculture: Applied forest ecology. 10th ed. New York (US): John Wiley \& Sons; 1997. p. 63-78.

26. González-Rodríguez H, López-Hernández JM, Ramírez-Lozano RG, Gómez-Meza MV, Cantú-Silva I, Sarquís-Ramírez JI, et al. Litterfall deposition and nutrient return in pine-oak forests and scrublands in northeastern Mexico. Madera y Bosques. 2019;25(3):1-16, doi: 10.21829/myb.2019.2531514

27. Lima N, Silva Neto CM, Calil FN, Souza KR, Moraes DC. Acúmulo de serapilheira em quatro tipos de vegetação no estado de Goiás. Enciclopédia Biosfera. 2015;11(22):39-46.

28. Soares PB, Carneiro TCJ, Calmon JL, Castro LO da C de O. Análise bibliométrica da produção científica brasileira sobre Tecnologia de Construção e Edificações na base de dados Web of Science. Ambiente Construído. 2016;16(1):175-85, doi: 10.1590/s1678-86212016000100067

29. Nave LE, Swanston CW, Mishra U, Nadelhoffer KJ. Afforestation effects on soil carbon storage in the United States: A synthesis. Soil Sci Soc Am J. 2013 May;77(3):1035-47, doi: 10.2136/sssaj2012.0236

30. Shimamoto CY, Padial AA, da Rosa CM, Marques MCM. Restoration of ecosystem services in tropical forests: A global meta-analysis. PLoS One. 2018 Dec;13(12):1-16, doi: 10.1371/journal.pone.0208523 
31. Meli P, Holl KD, Rey Benayas JM, Jones HP, Jones PC, Montoya D, et al. A global review of past land use, climate, and active vs. passive restoration effects on forest recovery. PLoS One. 2017 Feb 3;12(2):e0171368, doi: 10.1371/journal.pone.0171368

32. Chave J, Navarrete D, Almeida S, Álvarez E, Aragão LEOC, Bonal D, et al. Regional and seasonal patterns of litterfall in tropical South America. Biogeosciences. 2010 Jan 5;7:43-55, doi: 10.5194/bg-743-2010

33. Zhang H, Yuan W, Dong W, Liu S. Seasonal patterns of litterfall in forest ecosystem worldwide. Ecol Complex. 2014 Dec;20:8, doi: 10.1016/j.ecocom.2014.01.003

34. IBGE, Instituto Brasileiro de Geografia e Estatística. Manual técnico da vegetação brasileira. $2^{\mathrm{a}} \mathrm{ed}$. Vol. 39, Produção da Pecuária Municipal. Rio de Janeiro: IBGE; 2012. 271 p.

35. R Development Core Team. R: A Language and Environment for Statistical Computing. p. v. 4.0.3. Viena (AT): R Foundation for Statistical Computing; 2020.

36. Dudziak EA. Quem financia a pesquisa brasileira? Um estudo InCites sobre o Brasil e a USP. AGUIA, Agência USP de Gestão da Informação Acadêmica [Internet]. 23 jul 2018 [citado em 6 fev 2020]. Disponível em: https://www.aguia.usp.br/noticias/. Available from: https://www.aguia.usp.br/noticias/quem-financia-a-pesquisa-brasileira-um-estudo-incites-sobre-obrasil-e-a-usp/

37. Longo MHC, Souza CA, Solera ML, Ikematsu P, Campos SJAM, Bitar OY. Recuperação de áreas degradadas por mineração: Associação de técnicas de bioengenharia de solos com geração e manutenção de serviços ecossistêmicos. Rev IPT Tecnol e Inovação. 2019;3(12):6-17, doi: 10.34033/2526-5830v3n12-1

38. Viera M, Caldato SL, da Rosa SF, Kanieski MR, Araldi DB, dos Santos SR, et al. Nutrientes na serpilheira em um fragmento de Floresta Estacioanl Decidual, Itaara, RS. Ciência Florestal. 2010;20(4):611-9, doi: 10.5902/198050982419

39. Scheer MB, Gatti G, Wisniewski C. Nutrient fluxes in litterfall of a secondary successional alluvial rain forest in Southern Brazil. Rev Biol Trop. 2011;59(4):1869-82.

40. Costa BC, Suzuki PM, Martins WBR, Andrade VMS, Oliveira FA. Dinâmica da massa seca e propriedades químicas da liteira em Virola surinamensis e floresta sucessional na Amazônia oriental. Rev Verde Agroecologia Desenvolv Sustent. 2017 May;12(1):23, doi: 10.18378/rvads.v12i1.4407

41. de Holanda AC, Feliciano ALP, Freire FJ, de Sousa FQ, Freire SR O, Alves AR. Aporte de serapilheira e nutrientes em uma área de Caatinga. Ciência Florestal. 2017;27(2):621-32, doi: $10.5902 / 1980509827747$

42. Macedo MO, Resende AS, Garcia PC, Boddey RM, Jantalia CP, Urquiaga S, et al. Changes in soil C and $\mathrm{N}$ stocks and nutrient dynamics 13 years after recovery of degraded land using leguminous nitrogenfixing trees. Forest Ecol Manag. 2008 Apr;255:1516-24, doi: 10.1016/j.foreco.2007.11.007

43. Correia GGS, Martins SV, Neto AM, Silva KA. Estoque de serapilheira em floresta em restauração e em floresta atlântica de tabuleiro no sudeste brasileiro. Rev Árvore. 2016;40(1):13-20, doi: 10.1590/0100-67622016000100002

44. Lorenzo L, Campagnaro VH. Litterfall production as a function of planting seedlings system in a two years forest restoration area in the Costal-Plain of Caraguatatuba, São Paulo, Brazil. Rev Árvore. 2018;41(3):1-8, doi: 10.1590/1806-90882017000300019

45. Valenti MW, Cianciaruso MV, Batalha MA. Seasonality of litterfall and leaf decomposition in a Cerrado site. Brazilian J Biol. 2008;68(3):459-65, doi: 10.1590/S1519-69842008000300002

46. Vasconcelos SS, Zarin DJ, Araújo MM, Rangel-Vasconcelos LGT, de Carvalho CJR, Staudhammer CL, et al. Effects of seasonality, litter removal and dry-season irrigation on litterfall quantity and quality in eastern Amazonian forest regrowth, Brazil. J Trop Ecol. 2008;24(1):27-38, doi: $10.1017 / \mathrm{S} 0266467407004580$

47. Silva RM, Costa JMN, Ruivo MLP, Costa ACL, Almeida SS. Influência de variáveis meteorológicas na produção de liteira na Estação Científica Ferreira Penna, Caxiuanã, Pará. Acta Amazonica. 2009;39(3):573-82, doi: 10.1590/S0044-59672009000300012

48. Freitas ECS, Oliveira Neto SN, Fonseca DM, Santos MV, Leite HG, Machado VD. Deposição de serapilheira e de nutrientes no solo em sistema agrossilvipastoril com Eucalipto e Acácia. Rev Árvore. 2013;37(3):409-17, doi: 10.1590/S0100-67622013000300004

49. Schumacher MV, Côrrea RS, Viera M, de Araújo EF. Produção e decomposição de serapilheira em um povoamento de Eucalyptus urophylla x Eucalyptus globulus maidenii. Cerne. 2013 Jun;19(3):501-8, doi: 10.1590/S0104-77602013000300018

50. Ludvichak AA, Schumacher MV, Dick G, Momolli DR, de Souza HP, Guimarães C C. Nutrient return through litterfall in a Eucalyptus dunnii Maiden stand in sandy soil. Rev Árvore. 2016;40(6):1041-8, doi: 10.1590/0100-67622016000600009 
51. Alves GHZ, Santos RS, Figueiredo BRS, Manetta GI, Message HJ, Pazianoto LHR, et al. Misguided policy may jeopardize a diverse South brazilian environmental protection area. Biota Neotrop. 2019 Nov;19(1):1-7, doi: 10.1590/1676-0611-bn-2018-0574

52. Bozelli RL. The challenge of restoring tropical freshwater ecosystems. Acta Limnol Bras. 2019;31:110, doi: 10.1590/s2179-975x4619

53. Cavalcanti RQ, Rolim MM, de Lima RP, Tavares UE, Pedrosa EMR, Cherubin MR. Soil physical changes induced by sugarcane cultivation in the Atlantic Forest biome, northeastern Brazil. Geoderma. 2020 Jul;370:1-11, doi: 10.1016/j.geoderma.2020.114353

54. Martins WBR, Ferreira GC, Souza FP, Dionísio LFS, Oliveira FA. Deposição de serapilheira e nutrientes em áreas de mineração submetidas a métodos de restauração florestal em Paragominas, Pará. Floresta. 2018;48(1):37-8, doi: 10.5380/rf.v48i1.49288

55. Machado MR, Rodrigues FCMP, Pereira MG. Produção de serapilheira como bioindicador de recuperação em plantio adensado de revegetação. Rev Árvore. 2008 Feb;32(1):143-51, doi: $10.1590 / \mathrm{S} 0100-67622008000100016$

56. IBGE, Instituto Brasileiro de Geografia e Estatística. IBGE Cidades [Internet]. 2017 [citado em 22 mar 2020]. Disponível em: https://cidades.ibge.gov.br/brasil/pa/panorama

57. CONFAP, Conselho Nacional das Fundações Estaduais de Amparo à Pesquisa. FAPS [Internet]. 2020 [citado em 6 abr 2020]. Disponível em: https://confap.org.br/pt/faps

58. IBGE, Instituto Brasileiro de Geografia e Estatística. Áreas urbanizadas do Brasil [Internet]. 2017 [citado em $18 \mathrm{fev}$ 2020]. Disponível em: https://www.ibge.gov.br/apps/areas_urbanizadas/

59. Cross D, Thomson S, Sinclair A. Research in Brazil - A report for CAPES by Clarivate Analytics [Internet]. [local desconhecido]: Clarivate Analytics; 2018 [citado em 15 fev 2021]. Disponível em: https://observatoriodoconhecimento.org.br/wp-content/uploads/2019/04/04-Research-in-Brazil.pdf

60. Costa MG, Gama-Rodrigues AC, Zaia FC, da Gama-Rodrigues EF. Leguminosas arbóreas para recuperação de áreas degradadas com pastagem em Conceição de Macabu, Rio de Janeiro, Brasil. Sci Forestalis. 2014;42(101):101-12.

61. Alonso JM, Leles PSS, Ferreira LN, Oliveira NDSA. Aporte de serapilheira em plantio de recomposição florestal em diferentes espaçamentos. Ciência Florestal. 2015 Mar;25(1):1-11, doi: $10.5902 / 1980509817439$

62. IBGE, Instituto Brasileiro de Geografia e Estatística. Produção da extração vegetal e da silvicultura 2018. Prod Extr Veg e Silvic, Rio de Janeiro. 2018;33:1-8.

63. IBÁ, Instituto Brasileiro de Árvores. Relatório anual [Internet]. Brasília (DF): IBÁ; 2019 [citado em 19 dez 2020]. 79 p. Disponível em: https://iba.org/eng/datafiles/publicacoes/relatorios/ibarelatorioanual2019.pdf

64. Schumacher MV, Vieira M, Witschoreck R. Produção de serapilheira e tranferência de nutrientes em áreas de segunda rotação com floresta de Pinus taeda L. no município de Cambará do Sul, RS. Ciência Florestal. 2008;18(4):471-80, doi: 10.5902/19805098431

65. Viera M, Schumacher MV, Araújo EF, Corrêa RS, Caldeira MVW. Deposição de serapilheira e nutrientes em plantio de Eucalyptus urophylla $\times$ E. globulus. Floresta e Ambient. 2014;21(3):327-38, doi: 10.1590/2179-8087.053913

66. Viera M, Schumacher MV. Variação mensal da deposição de serapilheia em povoamento de Pinus taeda L. em área de campo nativo em Cambará do Sul - RS. Rev Árvore. 2010;34(3):487-94, doi: 10.1590/S0100-67622010000300012

67. Schumacher MV, Witschoreck R, Calil FN, Lopes VG. Manejo da biomassa e sustentabilidade nutricional em povoamentos de Eucalyptus spp. em pequenas propriedades rurais. Ciência Florestal. 2019;29(1):144-56, doi: 10.5902/198050985135

68. Camargo M, Giarrizzo T, Jesus A. Effect of seasonal flooding cycle on litterfall production in alluvial rainforest on the middle Xingu River (Amazon basin, Brazil). Braz J Biol. 2015 Aug;75(3 suppl 1):2506, doi: 10.1590/1519-6984.00514BM

69. Meir P, Mencuccini M, Binks O, da Costa AL, Ferreira L, Rowland L. Short-term effects of drought on tropical forest do not fully predict impacts of repeated or long-term drought: gas exchange versus growth. Philosophical Transactions of the Royal Society B: Biol Sci. 2018 Nov 19;373(1760):20170311, doi: 10.1098/rstb.2017.0311

70. Rezende CL, Scarano FR, Assad ED, Joly CA, Metzger JP, Strassburg BBN, et al. From hotspot to hopespot: an opportunity for the Brazilian Atlantic Forest Perspectives Ecol Conserv. 2018;16(4):20814, doi: 10.1016/j.pecon.2018.10.002

71. Sansevero JBB, Alonso JM, Booth MC, Bueno MM, Carvalho LS, Clemente N, et al. On the teaching of ecological restoration in Brazil: an analysis of postgraduate courses. Restor Ecol. 2017 Sep;26(5):997-1004, doi: 10.1111/rec.12662 
72. Guerra A, Reis LK, Borges FLG, Ojeda PTA, Pineda DAM, Miranda CO, et al. Ecological restoration in Brazilian biomes: Identifying advances and gaps. Forest Ecol Manag. 2020 Feb;458:1-7, doi: 10.1016/j.foreco.2019.117802

73. Villa EB, Pereira MG, Alonso JM, Beutler SJ, Leles PSS. Aporte de serapilheira e nutrientes em área de restauração florestal com diferentes espaçamentos de plantio. Floresta e Ambient. 2016;23(1):90-9, doi: 10.1590/2179-8087.067513

74. EMBRAPA Pantanal Impactos ambientais e socioeconômicos no Pantanal. EMBRAPA, Empresa Brasileiro de Pesquisa Agropecuária [Internet]. 2020 [citado em 14 fev 2020]. Disponível em: https://www.embrapa.br/pantanal/impactos-ambientais-e-socioeconomicos-no-pantanal

75. Marques ACA, Pinto Junior OB, Vourlitis GL. Avaliação de produção de serapilheira em planície inundável no Pantanal Mato-Grossense. Ensaios e Ciência C Biológicas, Agrárias e da Saúde. 2018;21(3):148, doi: 10.17921/1415-6938.2017v21n3p148-151

76. Costa CP, Costa SC, Cunha CN. Comparação da produção de serapilheira e fenologia em dois macrohabitat florestais no Pantanal, Mato Grosso, Brasil. Biodivers Bras. 2019;9(2):97-110, doi: 10.37002/biobrasil.v9i2.916

77. INPE, Instituto Nacional de Pesquisas Espaciais. A estimativa da taxa de desmatamento por corte raso para a Amazônia Legal em 2019 é de 9.762 km2 [Internet]. 2019 [citado em 9 ago 2020]. Disponível em: http://www.inpe.br/noticias/noticia.php?Cod_Noticia=5294

78. Ferreira LS, Cattânio JH, Jardim MAG. Efeito da topografia e da precipitação na florística e na produção de liteira em caxiuanã, Pará. Rev Árvore. 2015;39(6):995-1005, doi: 10.1590/010067622015000600002

79. Martins WBR, Vale RL, Ferreira GC, Andrade VMS, Dionísio LFS, Rodrigues RP, et al. Litterfall, litter stock and water holding capacity in post-mining forest restoration ecosystems, Eastern Amazon. Rev Bras Ciências Agrárias - Braz J Agric Sci. 2018 Sep;13(3):1-9, doi: 10.5039/agraria.v13i3a5546

80. Plataforma Sucupira. Cursos avaliados e reconhecidos [Internet]. 2020 [citado em 29 fev 2020]. Disponível

em: https://sucupira.capes.gov.br/sucupira/public/consultas/coleta/programa/quantitativos/quantitativoArea Conhecimento.jsf?areaAvaliacao $=42$

81. MEC, Ministério da Educação. Cadastro Nacional de Cursos e Instituições de Educação Superior Cadastro e-MEC [Internet]. 2020 [citado em $10 \mathrm{dez}$ 2020]. Disponível em: https://emec.mec.gov.br/

82. Machado MR, de Souza RC, Calvi GP, Piña-Rodrigues FCM, Leles PSS. Litterfall: A Bio-indicator for Edge Effect in a Semi-deciduous Seasonal Forest. Floresta e Ambient. 2018;25(3):1-10, doi: 10.1590/2179-8087.052817

83. Araújo VFP, Barbosa MRV, Araújo JP, Vasconcellos A. Spatial-temporal variation in litterfall in seasonally dry tropical forests in Northeastern Brazil. Braz J Biol. 2020 Aug;80(2):12, doi: 10.1590/1519-6984.192113

84. Brancalion PHS, Holl KD. Functional composition trajectory: A resolution to the debate between Suganuma, Durigan, and Reid. Restor Ecol. 2016;24(1):1-3, doi: 10.1111/rec.12312

85. Williams-Linera G, Bonilla-Moheno M, López-Barrera F, Tolome J. Litterfall, vegetation structure and tree composition as indicators of functional recovery in passive and active tropical cloud forest restoration. Forest Ecol Manag. 2021;493(April), doi: 10.1016/j.foreco.2021.119260

86. Zhu X, Zou X, Lu E, Deng Y, Luo Y, Chen H, et al. Litterfall biomass and nutrient cycling in karst and nearby non-karst forests in tropical China: A 10-year comparison. Sci Total Environ. 2021;758:143619, doi: 10.1016/j.scitotenv.2020.143619

87. Sayer EJ, Tanner EVJ. Experimental investigation of the importance of litterfall in lowland semievergreen tropical forest nutrient cycling. J Ecol. 2010;98(5):1052-62, doi: 10.1111/j.13652745.2010.01680.x

88. Qin Q, Wang H, Li X, Xie Y, Lei X, Zheng Y, et al. Corrigendum to "Spatial heterogeneity and affecting factors of litter organic carbon and total nitrogen over natural spruce-fir mixed forests in northeastern China”. Catena. 2019;176:430, doi: 10.1016/j.catena.2019.02.017

89. Lucas-Borja ME, Hedo de Santiago J, Yang Y, Shen Y, Candel-Pérez D. Nutrient, metal contents and microbiological properties of litter and soil along a tree age gradient in Mediterranean forest ecosystems. Sci Total Environ. 2019;650:749-58, doi: 10.1016/j.scitotenv.2018.09.079

90. Bufacchi P, Bizzo WA, Buckeridge MS, Franco-Jacome DL, Grandis A, Cambler AB, et al. Thermal degradation of leaves from the Amazon rainforest litter considering non-structural, structural carbohydrates and lignin composition. Bioresour Technol Reports. 2020 Sep;11:100490, doi: 10.1016/j.phrs.2020.104743

91. Quadros AF, Nordhaus I, Reuter H, Zimmer M. Modelling of mangrove annual leaf litterfall with emphasis on the role of vegetation structure. Estuar Coast Shelf Sci. 2019;218:292-9, doi: 10.1016/j.ecss.2018.12.012 
92. Williams MC, Wardle GM. Pine and eucalypt litterfall in a pine-invaded eucalypt woodland: The role of fire and canopy cover. For Ecol Manage. 2007 Dec;253(1-3):1-10, doi: 10.1016/j.foreco.2007.06.045

93. Lopes JFB, de Andrade EM, Lobato FAO, Palácio HAQ, Arraes FDD. Deposição e decomposição de serapilheira em área da Caatinga. Rev Agroambiente. 2009;3(2):72-9, doi: 10.18227/19828470ragro.v3i2.252

94. CONAMA, Conselho Nacional de Meio Ambiente. Resoluções do Conama: Resoluções vigentes publicadas entre setembro de 1984 e janeiro de 2012. Brasília (DF): MMA; 2012. BIOMAS - Diretrizes para o manejo, Resolução CONAMA n 9, de 24 de outubro de 1996; p. 108.

95. MMA, Ministério do Meio Ambiente. Mapas de cobertura vegetal dos Biomas brasileiros [Internet]. 2020 [citado em 6 abr 2020]. Disponível em: http://mapas.mma.gov.br/mapas/aplic/probio/datadownload.htm

96. Corrêa RS, Schumacher MV, Momolli DR. Deposição de serapilheira e macronutrientes em povoamento de Eucalyptus dunnii Maiden sobre pastagem natural degradada no Bioma Pampa. Sci Forestalis. 2013;41(97):65-74.

97. Rodrigues AM, Cecato U, Damasceno J, Galbeiro S, Gomes JAN, Avanzzi L. Produção, quantidade e concentração de macronutrientes do material morto de capim-mombaça, fertilizado com fontes de fósforo. Arq Bras Med Veterinária Zootec. 2009;61(2):445-51, doi: 10.1590/S010209352009000200023

98. Silva KA, Martins SV, Miranda Neto A, Lopes AT. Estoque de serapilheira em uma floresta em processo de restauração após mineração de bauxita. Rodriguésia. 2018 Jun;69(2):853-61, doi: 10.1590/21757860201869240

99. Sloan S, Meyfroidt P, Rudel TK, Bongers F, Chazdon R. The forest transformation: Planted tree cover and regional dynamics of tree gains and losses. Glob Environ Chang. 2019;59:1-18, doi: 10.1016/j.gloenvcha.2019.101988

100. Cordeiro IMCC, Schwartz G, de Barros PLC. Florestas secundárias: Manejo, distúrbios e sistemas agroflorestais. In: Cordeiro IMCC, Rangel-Vasconcelos LGT, Schwartz G, Oliveira FA, organizadores. Nordeste Paraense: Panorama geral e uso sustentável das florestas secundárias Belém (PA): EDUFRA; 2017. p. 255-76.

101. Mligo C. Post fire regeneration of indigenous plant species in the Pugu Forest Reserve, Tanzania. Glob Ecol Conserv. 2019;18:1-10, doi: 10.1016/j.gecco.2019.e00611

102. Choung Y, Choung MS. Biodiversity of burned forests is controlled by the sprouting ability of prefire species in Pinus densiflora forests. Ecol Eng. 2019 Feb;127:356-62, doi: 10.1016/j.ecoleng.2018.12.016

103. Rosa TFD, Scaramuzza WLMP, Feitosa IP, de Abreu FFM. Produção e decomposição de serapilheira em povamentos de Teca no Estado de Matos Grosso, Brasil. Ciência Florest. 2017;27(4):1117-27, doi: $10.5902 / 1980509830288$ 